\title{
Persuasive health educational materials for colorectal cancer screening
}

\author{
Militello, Laura G. ${ }^{1}$, Borders, Morgan R. ${ }^{1}$, Arbuckle, Nicole B. ${ }^{2}$, Flanagan, Mindy E. ${ }^{3}$, Hall, Nathan P. ${ }^{4}$, \\ Saleem, Jason J. ${ }^{5}$, \& Doebbeling, Bradley N. ${ }^{6}$ \\ ${ }^{1}$ Applied Decision Science, ${ }^{2}$ Caterpillar Trimble Control Technologies, LLC, ${ }^{3}$ Center for Health Services \& \\ Outcomes Research, IUPUI, ${ }^{4}$ S\&C Electric Company, ${ }^{5}$ Veterans Health Administration, ${ }^{6}$ School of Informatics \\ and Computing, IUPUI
}

\begin{abstract}
This paper describes an effort to design and evaluate persuasive educational materials for colorectal cancer (CRC) screening. Although CRC screening is highly effective, screening rates in the US remain low. Educational materials represent one strategy for educating patients about screening options and increasing openness to screening. We developed a one-page brochure, leveraging factual information from the Centers for Disease Control and Prevention (CDC) and national guidelines, and strategies for persuasion from the human factors and behavioral economics literatures. We evaluated the resulting brochure with adults over the age of 50. Findings suggest that the educational brochure increases knowledge of CRC and screening options, and increases openness to screening. Furthermore, no significant difference was found between the new one-page brochure and an existing multi-page Screen for Life brochure recommended by the CDC. We interpret these findings as indication that the more practical and potentially less intimidating one-page brochure is as effective as the existing multi-page Screen for Life brochure.
\end{abstract}

\section{INTRODUCTION}

The healthcare community is experiencing a growing shift toward engaging patients in managing care. As a result there is a push for educational materials and decision support tools that move beyond physicianor clinic-facing to patient-facing supports. Effective health promotion and health education materials are an important component of patient-centered care.

This paper describes the design and evaluation of a one-page educational brochure intended to improve patient knowledge of colorectal cancer (CRC) risk and screening options, and increase openness to screening. $\mathrm{CRC}$ is the second leading cause of cancer-related deaths that effect both men and women. Although screening is highly effective at detecting early stage treatable cancer and even has cancer prevention benefits, screening rates remain low. In light of this, our goal is to help patients understand their screening options and to persuade them to get screened via a one-page, easy to read brochure that the primary care provider may print and give to the patient, and/or display on a computer monitor to discuss during the patient exam.

In earlier phases of this research program, ethnographic observation (Saleem et al., 2009) and cognitive task analysis interviews (Lopez \& Militello, 2012) highlighted barriers to screening consistent with those found in the literature (Vernon, 1997; Beydoun \& Beydoun, 2008). Specifically, we focused on designing a brochure to address barriers including:

- Underestimation of CRC risk

- Lack of knowledge about testing options
- Overestimation of risks associated with colonoscopy

- Concern about discomfort during colonoscopy procedure

- Perception that CRC screening is expensive We drew from human factors (e.g., Feufel, Schneider, \& Berkel, 2010) and behavioral economics (e.g., Heath \& Heath, 2010) literatures to design an effective educational brochure for CRC screening. We then conducted an evaluation to assess whether the new brochure increases knowledge of CRC and openness to screening.

\section{Educational Brochure Development}

To design educational materials that persuade and motivate patients to get screened (Figure 1), we used factual information provided by the Centers of Disease Control and Prevention (CDC; Centers for Disease Control and Prevention [CDC], 2013), the U.S. Preventive Services Task Force (U.S. Preventive Services Task Force, 2008), and the American College of Gastroenterology (Rex et al., 2009). In addition, we incorporated persuasive elements recommended by relevant literatures including:

- An arousal statement to encourage reappraisal of the decision to delay getting screened. (Schneider, Rivers, \& Lyons, 2009).

- A path and direction for the patient to take the next step towards making an appointment (Heath \& Heath, 2010). 


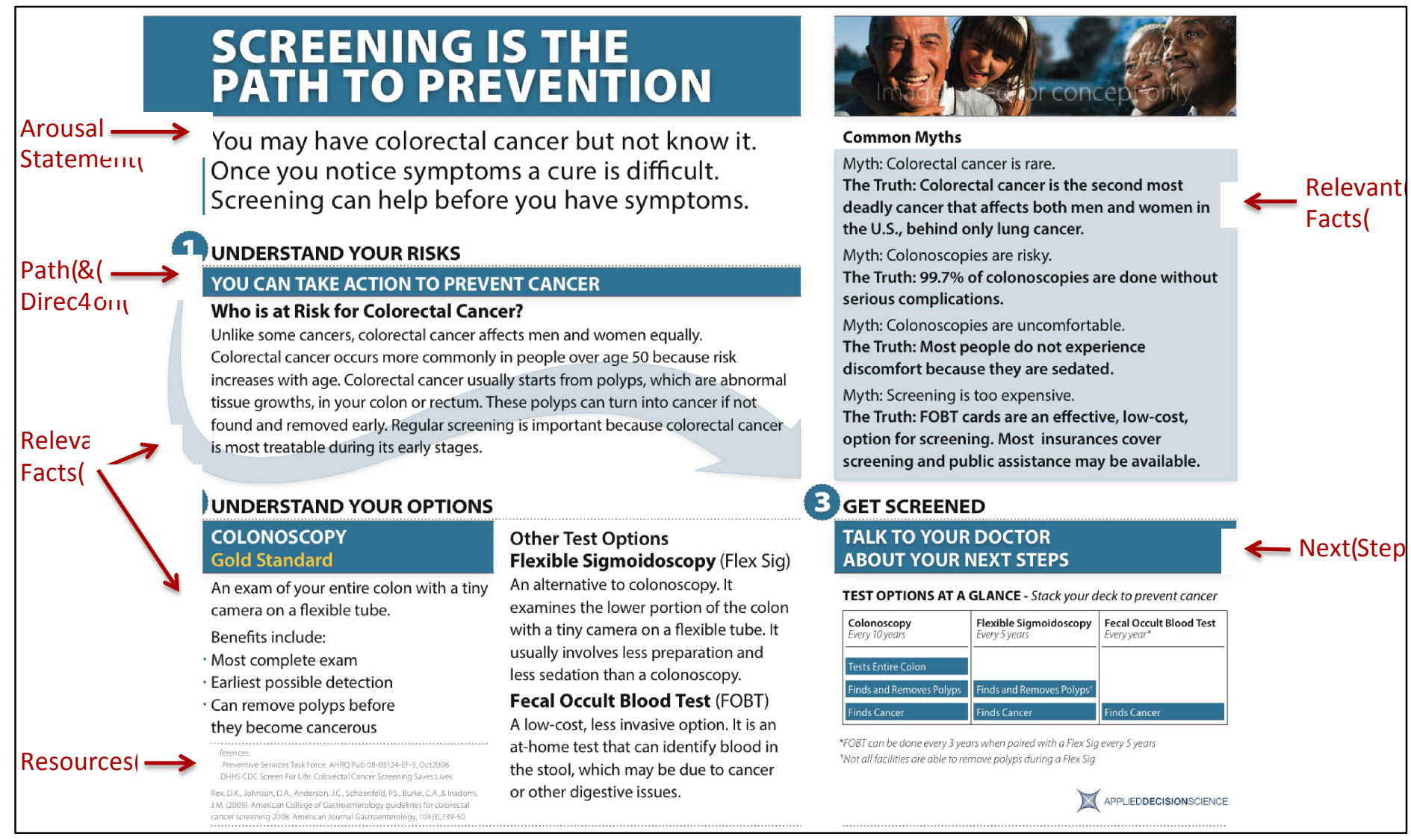

Figure 1: Applied Decision Science designed one-page CRC brochure

- Facts relevant to the audience to help build an appropriate mental model (Schneider, Rivers, \& Lyons, 2009).

- Available resources that help the person take the first step towards changing their behavior in the desired way (Heath \& Heath, 2010; Schneider, Rivers, \& Lyons, 2009).

Finally, we incorporated common misconceptions about CRC screening.

An important design goal was to limit our brochure to one page. Ethnographic observation findings in an earlier phase of this research program indicate that many primary care providers do not provide educational brochures about CRC screening to their patients. Interviewees reported a number of reasons including: lack of awareness of available educational brochures, dislike of brochures available, and expense of printing brochures. We reviewed educational materials available from our interviewees, as well as via an online search. We found that most were multi-page brochures. We reasoned that a one-page brochure is more likely to be read, easier for the physician to display on a monitor to discuss with patients, and less expensive to print and disseminate than a multi-page brochure. We hypothesized that both types of brochures would significantly increase knowledge of CRC screening and openness to receiving CRC screening. We further hypothesized that there would be no significant difference between the new one-page brochure and the existing multi-page brochure recommended by the CDC for either knowledge of or openness to CRC screening. Finally, we hypothesized that there would be a significant difference between the brochure types for ratings of likability, comprehension, readability, and appearance, as well as perceived influence.

\section{Evaluation Study}

We chose to use the CDC's Screen for Life brochure as a benchmark for our evaluation. This two-page brochure was developed as part of larger program incorporating a range of health promotion and educational materials aimed at increasing CRC screening in the US. We designed a study to assess whether our newly designed one-page brochure would increase knowledge of CRC and screening options, and openness to screening. Furthermore, we hoped to demonstrate that the one-page brochure was as effective as the CDC's Screen for Life brochure.

\section{METHOD}

\section{Participants}

One hundred and forty-seven volunteers participated in this study. Volunteers were recruited from the Osher 
Lifelong Learning Institute through emailed flyers, flyers posted in approved areas of the building, and through in-person recruitment. Participants were personally invited between classes and asked to participate in a survey funded by the Centers for Disease Control and Prevention about their opinions and knowledge of colorectal cancer screening. We recruited participants over 50 , as 50 is the age at which national guidelines recommend people with average risk begin CRC screening. Participants were offered $\$ 5$ as a token of appreciation for participating.

A total of 69 males (46.9\%) and 78 females (53.1\%), ranging in age from 50-95 (mean age $=72.21, \mathrm{SD}=$ 7.82) participated in this study. Detailed demographics for each group are presented in Table 1.

Table 1: Demographics by condition

\begin{tabular}{|c|c|c|c|}
\hline & & $\mathrm{CDC}$ & New \\
\hline & & Percent & Percent \\
\hline \multirow{2}{*}{ Race/Ethnicity } & Caucasion & 85 & 83 \\
\hline & Other & 5 & 4 \\
\hline \multirow{5}{*}{ Income } & Less than 19,999 & 3 & 4 \\
\hline & $20,000-39,999$ & 16 & 6 \\
\hline & $40,000-59,999$ & 15 & 22 \\
\hline & $60,000-79,999$ & 24 & 22 \\
\hline & Over 80,000 & 13 & 19 \\
\hline \multirow{5}{*}{ Education } & High School/GED & 9 & 7 \\
\hline & $\begin{array}{c}\text { Associate's } \\
\text { Degree/Certificate }\end{array}$ & 13 & 10 \\
\hline & Bachelors & 25 & 22 \\
\hline & Graduate & 41 & 50 \\
\hline & Other & 1 & 0 \\
\hline Personal History & Yes & 8 & 7 \\
\hline Family History & Yes & 28 & 17 \\
\hline Prior Screening & Yes & 91 & 90 \\
\hline \multirow{4}{*}{ Screening Type* } & Colonoscopy & 94 & 95 \\
\hline & Stool Card & 52 & 50 \\
\hline & $\begin{array}{c}\text { Flexible } \\
\text { Sigmoidoscopy }\end{array}$ & 33 & 27 \\
\hline & Other & 2 & 2 \\
\hline
\end{tabular}

*Participants selected all that applied. There are more responses than participants. Percents are calculated by number of particpants marking each test type/number of valid reponses.

\section{Materials}

The materials for this study included an informed consent, a pre- and post- test (Table 2), a brochure, and a receipt. The pre- and post-tests included Likert-type questions regarding openness to screening and multiple choice questions regarding colorectal cancer knowledge. Some items had multiple correct answers and were worth more than one point. The post-test also included a section about participants' ratings of the brochure, perceived influence of the brochure, and demographic information. The brochure ratings and perceived influence sections of the post-test used a Likert-type scale ranging from 1 (Strongly disagree) to 5 (Strongly agree). Brochure ratings examined likability, comprehensibility, readability, and appearance of the brochure. Perceived influence explored the importance of the brochure and whether the participant believed the brochure increased his or her knowledge of and

Table 2: Pre and post-test items

\begin{tabular}{|c|c|}
\hline & Pre- and post-test items \\
\hline & Openness \\
\hline & $\begin{array}{l}\text { How likely are you personally to get screened for colorectal } \\
\text { cancer? }\end{array}$ \\
\hline & How likely are you to have a colonoscopy? \\
\hline & $\begin{array}{l}\text { How likely are you to discuss colorectal cancer with your } \\
\text { doctor? }\end{array}$ \\
\hline & $\begin{array}{l}\text { How likely are you to schedule an appointment with you } \\
\text { doctor to discuss your screening options? }\end{array}$ \\
\hline & Knowledge \\
\hline & What part(s) of the body does colorectal cancer affect? \\
\hline & How does colorectal cancer usually begin? \\
\hline & $\begin{array}{l}\text { At what age should most people begin to get screened for } \\
\text { colorectal cancer? }\end{array}$ \\
\hline & What is a colon polyp? \\
\hline & Is colorectal cancer treatable? \\
\hline & How common is colorectal cancer? \\
\hline & Colorectal cancer affects: (men, women, both, unsure) \\
\hline & $\begin{array}{l}\text { Which of the following are recommended screening tests for } \\
\text { colorectal cancer? }\end{array}$ \\
\hline & What does a stool card (FOBT, FIT) specifically test for? \\
\hline & $\begin{array}{l}\text { During which procedure(s) can a doctor remove a polyp if } \\
\text { one is found? }\end{array}$ \\
\hline & $\begin{array}{l}\text { How often should a person have a colonoscopy (assuming no } \\
\text { other risk factors)? }\end{array}$ \\
\hline & $\begin{array}{l}\text { How often should a person complete a stool card (FOBT, } \\
\text { FIT) (assuming no other risk factors and/or screening } \\
\text { interventions)? }\end{array}$ \\
\hline & $\begin{array}{l}\text { How often should a person have a flexible sigmoidoscopy } \\
\text { (assuming no other risk factors)? }\end{array}$ \\
\hline & $\begin{array}{l}\text { Why is it important to get screened early for colorectal } \\
\text { cancer? }\end{array}$ \\
\hline & Brochure Ratings \\
\hline & Likability: I like the brochure I just read. \\
\hline & $\begin{array}{l}\text { Overall comprehension: I find the brochure easy to } \\
\text { understand. }\end{array}$ \\
\hline & Readability: I find the brochure easy to read. \\
\hline & Appearance: I find the brochure visually appealing. \\
\hline & Perceived Influence \\
\hline & $\begin{array}{l}\text { Importance: The brochure increased my knowledge of the } \\
\text { importance of colorectal cancer screening. }\end{array}$ \\
\hline & $\begin{array}{l}\text { Options: The brochure increased my knowledge of colorectal } \\
\text { cancer screening options. }\end{array}$ \\
\hline & $\begin{array}{l}\text { Openness: The brochure increased my openness to talking to } \\
\text { my doctor about screening options. }\end{array}$ \\
\hline
\end{tabular}


openness to screening. The brochures used included the CDC's two-page Screen for Life brochure and the new, one-page brochure.

\section{Procedure}

Participants were randomly assigned to either the CDC two-page brochure group or the new one-page brochure group. Participants began the study by reading and signing an informed consent. The researchers answered questions the participants had and explained the study. Participants completed a pre-test about their current colorectal cancer knowledge and openness to screening. Then participants read either the new, onepage brochure or the two-page CDC brochure. After reviewing a brochure, participants completed a post-test, rated the brochure, and answered demographic questions. Participants were then given five dollars and asked to sign a receipt. Finally, a researcher debriefed participants and answered any questions.

\section{Analysis}

Demographic variables were tested for any relation to change in knowledge and openness using univariate regression models. Parameters were estimated using Full Information Maximum Likelihood to account for missing data. Brochure groups were compared on pretest knowledge and openness using independent t-tests.

To test for changes in knowledge and openness (across both brochure groups), pre-test scores and posttest scores were compared using paired t-tests. To test for a differential effect of the two brochures on changes in knowledge and openness, independent t-tests were conducted on change scores for knowledge and openness. Finally, we compared the brochure groups on their ratings for likability, comprehension, readability, appearance, and perceived influence using independent t-tests. Likewise, brochure groups were compared on ratings for importance, options, and openness using independent t-tests. Bonferroni adjustments were used to account for multiple comparisons.

\section{RESULTS}

The results showed that there was a significant change in knowledge, $\mathrm{t}(146)=13.37, \mathrm{p}<.0001$ (Figure $2)$. Knowledge scores on the post-test $(M=15.84 S D=$ 2.33) were higher than knowledge scores on the pre-test $(M=13.14, S D=2.76)$. This indicates that reading either the multipage CDC Screen for Life brochure or the new one-page brochure increased knowledge of CRC screening. Brochure type did not affect the amount of change in knowledge scores, $t(144)=-0.75, p=0.45$.

The results for openness were similar to that of knowledge (Figure 2). The results showed a significant change in openness, $t(145)=3.10, p=.002$. Openness scores on the post-test $(M=4.33, S D=.99)$ were higher than openness scores on the pre-test $(M=4.23, S D=$ .93). Brochure type did not affect the amount of change in openness scores, $t(145)=1.15, p=0.25$.

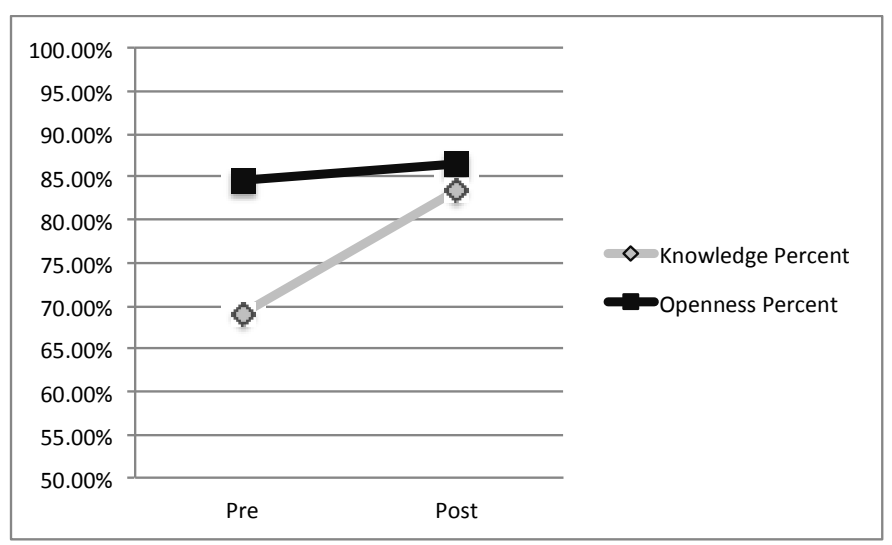

Figure 2: Pre and post scores in percent

We also explored the participants' ratings of the brochures on four dimensions: likability, overall comprehension, readability, and appearance. Both brochures received positive ratings on all four dimensions. Means on all dimensions exceeded 3.5 (Figure 3), where 3 indicated a neutral rating, anything above 3 represented a positive rating, and anything below 3 represented a negative rating. Each participant rated only the brochure that he or she read. There were no significant differences between the Screen for Life brochure and the new one-page brochure on these four dimensions (all $t<0.90$, all $p>.40$ ).

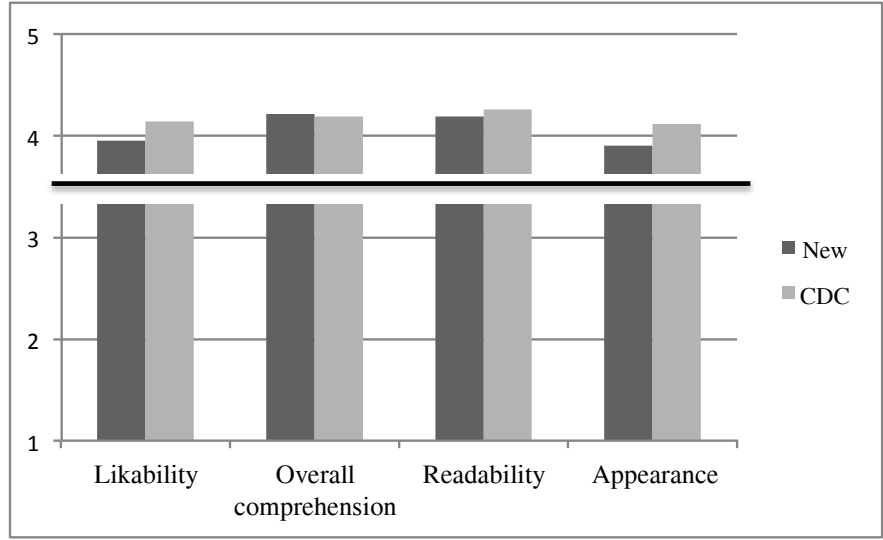

Figure 3: Scores on brochure ratings where 5 represents the most positive response and 1 represents the most negative response.

We examined the perceived influence of the brochures using questions addressing: perceived change in knowledge about the importance of screening, perceived change in knowledge about the various screening options, and perceived change in openness to

talking to the doctor about screening options. Each participant rated only how the brochure that he or she 
read affected him or herself. Means on all dimensions exceeded 3.5 (Figure 4), where 3 indicated a neutral rating, anything above 3 represented a positive rating, and anything below 3 represented a negative rating (see Figure 3), The results showed no significant difference between the Screen for Life brochure and the newly designed one-page brochure (all $t<1.5$, all $p>.15$ ).

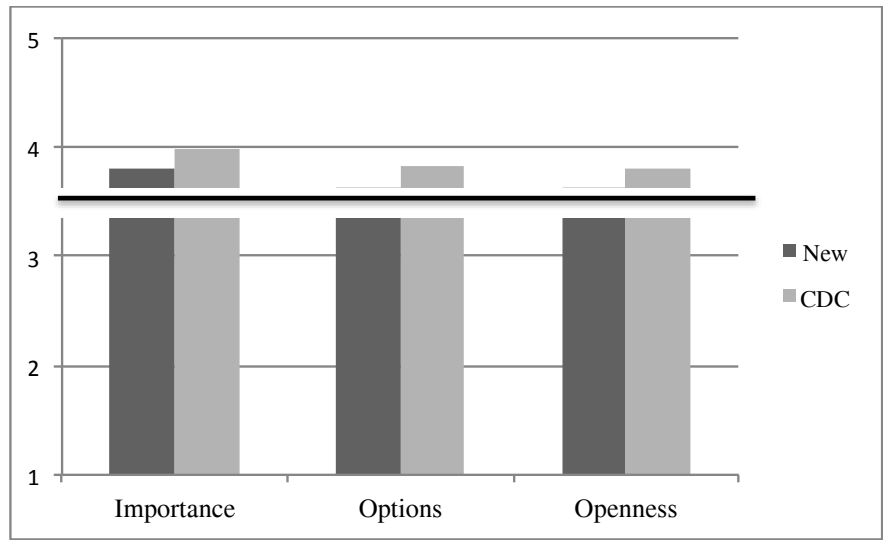

Figure 4: Scores on perceived influence questions where 5 represents the most positive response and 1 represents the most negative response.

\section{DISCUSSION}

Findings indicate that the educational materials increase knowledge of and openness to CRC screening. Further, we were encouraged that there was no significant difference between the two brochures, suggesting that the one-page and CDC brochures may be equally effective. We believe there are practical advantages to a one-page brochure in that it is easier to print, view on a screen, and perhaps less daunting to read.

Because this evaluation was limited to a relatively homogenous sample of middle class Caucasians, a next step is to explore personalized educational materials aimed at special populations. We have begun to explore and design personalized educational materials that are tailored to the intended audience's concerns and to their own personal information and history. Facets being explored include displaying the person's name, testing history, and the location of the nearest or recommended testing facility. We believe that personalizing educational materials will be even more persuasive and memorable than basic materials tailored to the general population's concerns. In addition, future research could explore the use of other educational medias such as public service announcements.

\section{ACKNOWLEDGMENTS}

The authors would like to thank the Centers for Disease Control and Prevention for funding the project under which this work was performed (Contract No 2002012-52902), especially Don Haverkamp for his technical guidance and support. Views stated in this paper are those of the authors and not the Centers for Disease Control and Prevention, the Department of Veterans Affairs or the U.S. government. The authors would like to thank Tamera Schneider for her review and suggestions for the design of the one-page brochure. In addition, the authors would like to acknowledge Steve Wolf for his input to the design and evaluation.

\section{REFERENCES}

Lopez, C. \& Militello, L. (2012). Colorectal cancer screening decision support: Final report. In support of Contract No: 200-2011-M-41884. Prepared for the Centers for Disease Control and Prevention. Cincinnati, OH: Applied Decision Science.

Beydoun, H. \& Beydoun, M. (2008). Predictors of colorectal cancer screening behaviors among average-risk older adults in the United States. Cancer, Causes, \& Control, 19(4), 339-359.

Centers for Disease Control and Prevention. (2013). Colorectal (colon) cancer. Retrieved from http://www.cdc.gov/cancer/colorectal/

Feufel, M.A., Schneider, T.R., \& Berkel, H.J. (2010). A field test of the effects of instructions designon colorectal cancer self-screening accuracy. Health Education Research, 25(5), 709-723.

Heath, C., \& Heath, D. (2010). Switch: How to change things when change is hard. New York, NY: Broadway Books.

Rex, D.K., Johnson, D.A., Anderson, J.C., Schoenfeld, P.S., Burke, C.A.,\& Inadomi, J.M. (2009). American College of Gastroenterology guidelines for colorectal cancer screening 2008. American Journal Gastroenterology, 104(3),739-50.

Saleem, J.J., Militello, L.G., Arbuckle, N., Flanagan, M., Haggstrom, D.A., Linder, J.A., \& Doebbeling, B.N. (2009). Provider perceptions of colorectal cancer screening decision support at three benchmark institutions. AMIA Annual Symposium Proceedings, 558-62.

Schneider, T.R., Rivers, S.E., \& Lyons, J.B. (2009). The biobehavioral model of persuasion: Generating challenge appraisals to promote health. Journal of Applied Social Psychology, 38(8), 1928-1952.

US Preventive Services Task Force. (2008). AHRQ Pub 0805124-EF-3.

Vernon, S. (1997). Participation in colorectal cancer screening: A review. Journal of the National Cancer Institute, 89(19), 1406-1422. 